\title{
Dan Jaffé, Essai sur l'interprétation et la culture talmudiques. Femmes et familles dans le Talmud
}

Paris, 2013, Éditions du Cerf, coll. « Patrimoine/judaïsme »,258 p.

Daniel Vidal

\section{(2) OpenEdition}

\section{Journals}

Édition électronique

URL : http://journals.openedition.org/assr/26462

DOI : $10.4000 /$ assr.26462

ISSN : $1777-5825$

Éditeur

Éditions de l'EHESS

Édition imprimée

Date de publication : 31 décembre 2014

Pagination : 224

ISBN : 978-2-7132-2467-6

ISSN : 0335-5985

Référence électronique

Daniel Vidal, « Dan Jaffé, Essai sur l'interprétation et la culture talmudiques. Femmes et familles dans le Talmud ", Archives de sciences sociales des religions [En ligne], 168 | 2014, mis en ligne le 30 avril 2015, consulté le 22 septembre 2020. URL : http://journals.openedition.org/assr/26462 ; DOI : https:// doi.org/10.4000/assr.26462

Ce document a été généré automatiquement le 22 septembre 2020

(C) Archives de sciences sociales des religions 


\section{Dan Jaffé, Essai sur l'interprétation et la culture talmudiques. Femmes et familles dans le Talmud}

Paris, 2013, Éditions du Cerf, coll. « Patrimoine/judaïsme »,258 p.

Daniel Vidal

\section{RÉFÉRENCE}

Dan Jaffé, Essai sur l'interprétation et la culture talmudiques. Femmes et familles dans le Talmud, Paris, 2013, Éditions du Cerf, coll. « Patrimoine/judaïsme »,258 p. 
1 De la controverse avant toute chose, de la subversion portée au cœur de la Loi, de la déconstruction du Texte jusqu'à son « renoncement»: voici quelques traits caractéristiques du Talmud, cette production foisonnante, contradictoire, irrépressible, d'interprétations de la Torah, la loi écrite, par les Sages d'Israël après la destruction du Second Temple en 70 de l'ère chrétienne. Cette catastrophe sociale, cultuelle et culturelle, et l'exil qui s'ensuit, provoquent le fractionnement du peuple juif dépossédé de ses repères civiques et institutionnels, en même temps qu'une grande effervescence intellectuelle le traverse. Il convient en effet de réunifier ce que le trauma politique a fait éclater, et de fonder à nouveaux frais un "point d'ancrage identitaire » dans les conditions de cette

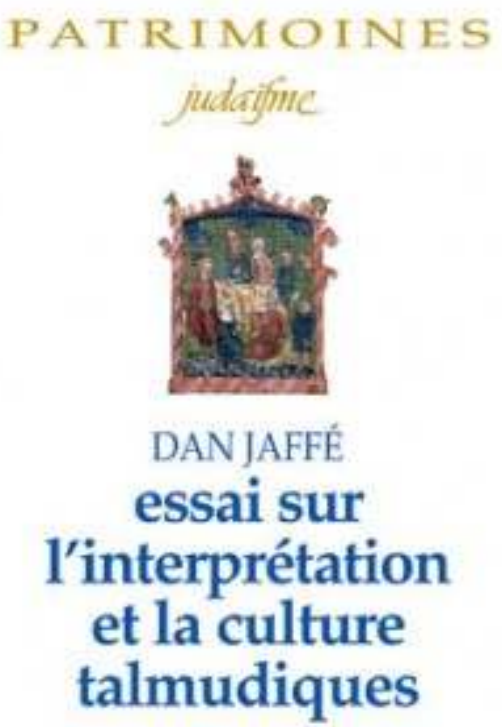

Femmes et familles dans le Talmud $\operatorname{cerf}$ perte générale des référents. Le Talmud (la Mishna, loi orale et son développement, la Guemara) sera l'instrument de cette renaissance. Mis en écrits, les commentaires de la Torah seront l'objet d'études et de débats qui vont définir les conditions d'une lecture $\mathrm{du}$ texte biblique qui apparaîtra très vite vigoureusement contestataire. Dans son intention d'expliciter la Torah, afin d'en rendre les préceptes et les enseignements compatibles avec les conditions réelles de la vie quotidienne, collective et personnelle, le Talmud est bien plus qu'une relecture exigeante de la Bible : il va en proposer une véritable réécriture. Passionnant destin que ce procès d'insoumission qui loge au centre du texte divin l'acte souverain de l'émancipation de la Loi, dont Dan Jaffé analyse la dimension herméneutique, et les nouvelles configurations de sens qui en procèdent.

2 Il n'est pas au départ, dans les débats internes entre les Sages, de principe unifié de lecture. Le raisonnement talmudique se fonde au contraire sur une «culture du désaccord ", qui ouvre un immense champ de réflexions sur le statut du savoir, ses conditions d'émergence, et la raison de son instabilité de principe. Toutes questions auxquelles les sciences sociales sont aujourd'hui confrontées. Le Talmud n'entend pas livrer un socle achevé de "vérités", mais, tout entier défini comme "désir de connaissance ", il ne s'enclot jamais en système de réponses, quand seule lui importe la question. De là, cette quête en effet toujours recommencée, qui à vrai dire ne connaît de cesse. "Mouvement perpétuel », note l'auteur, qui fait de toute interprétation un moment singulier dans une chaîne continue de commentaires qui s'élaborent dans la "dispute» de chacun avec tout autre. C'est par ce principe de reprise permanente des débats que le Talmud acquiert une autorité plus grande que la Torah. Si la « loi orale » l'emporte sur la " loi écrite ", et les études des Sages sur les exégètes de la Bible, c'est parce qu'elles répondent aux interrogations d'un peuple déconcerté, dans les situations critiques auxquelles la Loi écrite ne propose que des issues impossibles. "Sans la Mishna, écrit Jaffé, la Torah serait inintelligible ». C'est dire que le Talmud n'interprète 
le texte divin qu'en le précipitant dans le monde réel, quand même il faudrait en transgresser la lettre et l'esprit qui s'y noue.

3 Né de la Bible, le Talmud parfois s'y oppose par le jeu contrasté des références entrelacées, et le travail incessant d'élucidation du Texte auquel il se livre. Son étude, à quoi chacun est convié, constitue "le moyen de cohésion sociale du monde juif » au lendemain de la destruction du Temple. De l'« être » à la « lettre », Dan Jaffé définit une identité partagée : «La perpétuation de l'Être juif passait par la lettre que représente le Talmud ». Si la Mishna fait autorité, ce n'est pas de proposer une vérité capable de répondre aux difficultés que rencontre le peuple dans son existence quotidienne, mais de laisser précisément en suspens le temps de la réponse, ouvrant toujours plus la question à la pluralité de ses significations. Et cette ouverture se décide dans la subjectivité même des Sages, leur singularité, leur expérience unique et fragile. Seule une telle implication personnelle permet de "retirer à la Loi son caractère exclusivement divin pour lui conférer un aspect humain». Hors l'homme, point de vérité biblique. La «créature» au prix du «créateur». Inapplicables en l'état, les versets bibliques doivent passer l'épreuve d'une déconstruction radicale. «Faire éclater le Texte ", note l'auteur, afin "d'en exposer les multiples facettes ", et qu'un message viable puisse en être proposé. La Loi est alors cet « écrin narratif » où le Talmud se loge comme son défi le plus haut. Par lui, le passage est ouvert d'une "révélation divine directe, à une autre, fondée sur l'étude des Sages » et leur interprétation. Parcours herméneutique où le commentaire sans cesse sur lui-même se retourne, "critique de la critique », opération jamais achevée, comme il en va d'une œuvre d'art s'effectuant.

$\mathrm{Si}$ « l'éthique travaille le texte ", et si l'on peut ainsi définir un fondement stable à un processus de lecture qui n'en requerrait nul autre, c'est par ce que le Talmud doit imaginer des solutions pratiques à des situations de conflit pour lesquelles la Bible n'édicte que des préceptes impossibles ou/et impensables dans le cours réel des choses de la vie. Du «fils dévoyé et rebelle », la Loi dit : qu'il soit lapidé. Comment décider, à partir de cet impératif, d'une conduite acceptable par le groupe social? Toute une entreprise de "déminage » est mise en place, analyse l'auteur, qui décompose le texte, en déplace les lignes de force, en désamorce la pente fatale, et déploie autour et contre le Texte un enchaînement de commentaires qui met en crise le sens premier et lui fait objection. Le Talmud est alors bien cette objection fondamentale opposée à la lettre et l'esprit de la Torah. La lettre, il va de soi. L'esprit aussi bien, dans la mesure où la Mishna remonte à la source de la Loi pour en «déraciner (l') enseignement inintelligible ». Dieu «désenclavé de la lettre qui l'enferme»: voilà le triomphe de l'éthique et de la subjectivité dont Dan Jaffé souligne la fonction centrale dans l'acte même de connaissance. Et dans son accomplissement pratique. Et cela peut s'entendre comme équivalent au conflit de la Loi de la Cité et de la protestation éthique de la personne, Créon contre Antigone. Parler le «langage des hommes » ne se peut qu'au revers de Dieu, trop de "notions existentielles» l'éloignant du verbe divin. "Comprendre, écrit D. Jaffé, l'abîme qui sépare la faute de son châtiment", le dévoiement du fils, de sa mise à mort. En ce sens l'éthique est "l'au-delà du Texte ", l'au-delà de la Loi. Une Loi, précisait J. Derrida dans son commentaire du Procès de Kafka, « inopérante et inconcevable », et cependant toujours « désirable ».

5 Il est dans le Talmud une "liberté herméneutique totale ", note Jaffé, qui ne peut s'exercer que dans «le sacrifice de la Lettre » au terme d'une double épreuve. La Bible est mise en tous ses états, tous ses éclats. Texte fragmenté, dépossédé de son autorité, 
chaque terme étant questionné dans tout le spectre de ses significations, chaque commentaire à son tour remis en travail et en doute par tout autre entrant en intrigue avec lui. Si cependant les Sages ne peuvent «annuler radicalement l'injonction biblique ", ils la réduisent "à l'absurde». Alors le «fils rebelle» n'est plus le " personnage » central d'une crise virtuelle, mais le «fantôme» d'une histoire réelle, une fiction dont la seule valeur est théorique. Il en va de même du cas de "la femme adultère ", promise elle aussi par la Loi à une humiliation et une violence collectives, contrainte de boire "les eaux amères de la malédiction », breuvage d'infamie. Là donc la Loi doit encore être transgressée pour être viable, et faire ainsi l'objet à l'infini de remaniements et de déplacements, de réductions intuitives et de "rapprochements arbitraires ", qui sont le travail même du Talmud. Peut-on aller plus loin encore, dans la mise à l'épreuve du Texte ? Oui, sans doute : jusqu'à la suppression de la Loi « afin de maintenir la relation au divin ». Au-delà de la Loi est l'éthique. Au-delà du Texte est le «divin». L'éthique comme valeur fondamentale du sujet humain. Le divin comme espace même du «sujet absolu». Le Talmud est ajointement de l'un à l'autre. C'est à cette condition qu'il permet à un peuple en exil de lui-même, de véritablement reprendre son cours dans l'histoire. Il constitue, précise D. Jaffé, « un corpus narratif dont l'un des objectifs est la réorganisation radicale du judaïsme vécu en tant que religion sans sacrifice, sans Temple, et sans sacerdoce ». L'on comprend mieux alors la transition qui s'opère entre le culte public - le Temple - et ce véritable culte privé que constitue l'étude vouée au Talmud. En lui, toute créativité est en effet possible, dès lors que la réécriture critique de la Bible, allant jusqu'au renoncement même du Texte, est la condition de toute nouvelle parole pour peuple renaissant. 